diameters less than $100 \mu$. When flashed at fairly low intensities, metal foils 5-10 $\mu$ thick were etched, revealing microstructure of the metal. At higher intensities the foil melted into a small droplet, and at still higher intensities vaporized ${ }^{6}$. Powdered coal has been vaporized and pyrolysed by flashing in vacuo and in hydrogen and halogen atmospheres ${ }^{6}$.

Flash heating has been used to pyrolyse methane in the presence of $7 \cdot 5 \mu$ tungsten wire; hydrogen, ethane, ethylene, acetylene and carbon were formed ${ }^{6}$. Explosions have been initiated in the systems methane-oxygen and hydrogen-oxygen by flash. ing these gas mixtures in the presence of borosilicate glass wool. While glass wool is certainly not a simple black-body absorber in triggering these explosions, nevertheless, the glass wool was heated to fusion temperatures ${ }^{6}$.

Mineral oil has been flash pyrolysed using suspended molybdenum (less than $74 \mu$ ) and carbon (less than $36 \mu)$ powders, glass wool $(8 \mu)$ and tungsten wool $(7 \cdot 5 \mu)$ as absorbers. Flashing above a threshold energy caused the oil to become black with suspended carbon, effervesce, and fluoresce when excited by 3661-A. radiation. Fig. 4 shows two borosilicate glass tubes of mineral oil flashed once at $10,000 \mathrm{~J}$. The tube with the opaque black suspension contained 25 metres of $7 \cdot 5-\mu$ tungsten wire, whereas the other had no absorbing material present before flashing. If the solids are filtered from the oil, an absorption spectrum is obtained which is similar to that of an oil degraded in service as a high-voltage insulator.

If a slurry of zine dust in mineral oil or glycerine is flashed, the metal is evaporated and re-deposited in finer form but without degradation of the matrix. Zine boils at $907^{\circ}$ C.; thus, in the vaporizationredeposition process it must reach a temperature sufficient to pyrolyse the hydrocarbon. Upon flashing zinc dust suspended in polyethylene, zinc was evaporated, but no degradation of the polymer took place. It is possible that the quenching of free radicals by zinc vapour occurs, as in the Paneth mirror removal reaction?.

Dark particles smaller than $90 \mu$ in diameter embedded in polymers become sufficiently hot to cause degradation when flashed above $10^{3} \mathrm{~J}$. Carbon, hydrogen, water, carbon monoxide, carbon dioxide, methane, acetylene, ethylene, ethane, and small amounts of higher hydrocarbons are produced when unclean polyethylene is flashed 4,8 . Since the carbon formed with one flash acts as an absorber during the next flash, the amount of degradation in polymers is cumulative with the number of flashes. Empirically, the total amount of gas formed from polyethylene is nearly proportional to the square of the number of flashes ${ }^{8}$. In addition, wax-like degradation products are expelled from the polymer during flashing, and fluorescent materials are deposited near the carbonized centres.

In gaseous or vacuum matrices, absorbing sheets or cylinders, such as wires, fibres or filaments, are the most convenient experimentally since they have known dimensions and shape, are self-supporting, and can be placed in known orientations in the system. Particulate absorbers may be suspended in liquid systems, but for careful work they always show the difficulties associated with agglomeration, poorly known shape, and a distribution of diameters. In very viscous liquids or polymers it is always difficult to incorporate materials without accompanying gas pockets or other disturbances, and reproducibility is never high. In most systems cylindrical absorbers are the most easily handled experimentally.

The experiments described here demonstrate the applicability of rapid heating by flash illumination of absorbers of small dimensions. Further, the similarity of the time-scale and experimental arrangements to the flash photolysis technique ${ }^{2}$ suggests its use for preparing free radicals in systems which do not absorb light from the usual flash sources. The chemical effects are somewhat similar to those of shock waves but can be produced in liquid and solid systems as well as gases, to form much greater instantaneous volumes of reaction intermediates. In effect, heating by flash illumination is a heterogeneous sensitization which transfers optical energy from photons unable to cause discrete photochemical processes via thermal excitation into chemical energy, an over-all process quite analogous to true homogeneous sensitization. However, unlike flash photolysis with or without sensitizers, flash heating of absorbing bodies depends little on wave-length of the flash; it often has a threshold intensity below which no discernible reaction occurs, and it has present a hot reactive interface or, in more extreme cases, hot vapour from the absorber, to complicate the reaction.

${ }^{1}$ Leemans, A., and Kompfner, R., Vacuum (London), 1, 203 (1951). Weisberg, L. R., and Gunther-Mohr, G. R., Rev. Sci. Instr., 26,
896 (1955).

${ }^{2}$ Eggert, J., Physik. Bl., 10, 549 (1954); J. Phys. Chem., 63, 11 (1959),

${ }^{3}$ Christie, M. I., and Porter, G., Proc. Roy. Soc., A, 212, 390 (1952).

${ }^{4}$ Lundberg, J. L., and Nelson, L. S., Nature, 179, 367 (1957). 5 Lundberg, J. L., Nelson, L. S., and Hellman, M. Y., Proc. Third
Conf. Carbon, Buffalo, New York, 1957, pp. 411 418 (Pergamon Press, 1959).

${ }^{6}$ Nelson, L. S., and Lundberg, J. L., J. Phys. Chem., 63, 433 (1959).

'Paneth, F. H., and Hofeditz, W., Chem. Ber., 62B, 1335 (1929).

${ }^{8}$ Nelson, L. S., and Kuebler, N. A., American Chemical Society Meeting, Chieago (September 12, 1958). - Norrish, R. G. W., and Thrush, B. A., Quart. Rev. Chem. Soc., 10.
149 (1956).

\title{
DARWINISM AND THE STUDY OF SOCIETY
}

$T^{o}$ O mark the centenary of "The Origin of Species", a conference was arranged at the instigation of the Scottish Branch of the British Sociological Association and held in Adam House, Chambers Streot, Edinburgh, during April 8-10. Originally it was envisaged as something of an investigation into the origins and development of Social Darwinism. This intention underwent some change at the hands of the ad hoc organizing committee of natural and social scientists from Scottish universities, but the public purpose of the conference emerged as a discussion of the effect of the publication of "The Origin of Species" on social theorizing, and an examination of the present bearing of biology on sociology.

These two main themes became at times closely interwoven, and the core of the conference discussions was, in many ways, Prof. C. H. Waddington's paper on "The Human Evolutionary System". This was nothing less than an attempt to fit Social Darwinism out in modern dress : to read human history and social 
development in the light of the biologist's interpretation of evolution.

Waddington began with a concise but extremely lucid exposition of the evolutionary system, under four headings: (1) exploitation, the 'choice' of a particular environmental niche out of the range of possibilities open to any creature, and the possible modification of that environment ; (2) epigenesis, the complex and interacting processes by which the development of the fertilized egg into the mature organism is controlled, processes which possess resilience in surmounting obstruction or damage, tend towards the coherent organization of all the single parts, and seek pre-determined end-points of growth; (3) genesis, the transmission of separable hereditary characteristics actually or potentially present in the parents; (4) natural selection, the environmental factors which may favour, challenge, or destroy the possibilities of reproduction. This four-fold system applies, of course, to man as to other animals, but Waddington proposed that it might provide a theoretical model, or at least a number of interesting suggestions, for the interpretation of the evolutionary processes apparent in human history. If one sees the creation of the mature organism from the fertilized egg as a continuous series of chemical accretions and processes going on under controls established by the 'information' stored in chromosomes, then, at this level of abstraction, the theoretical system devised by biologists to account for evolutionary change might conceivably apply to the changes occurring in the more complex, but essentially similar, passage of information from generation to generation of men by a multiplicity of extra-genetic channels.

For example, the genetic make-up of a population tends to resist disturbances which might change it by natural selection; after such a disturbance is withdrawn, the frequencies of genes in the gene pool return towards their previous values. "Something near to this biological genetic homoeostasis in its strict sense . . . are the somewhat nebulous, but often easily recognizable, qualities which are often spoken of as national characteristics, such as Jewishness, or Indianness". Another specific analogy is suggested by the process of introgressive hybridization in plants, which results from the persistence or loss of whole chromosomes. When this happens, a whole "chunk of genetic information", more or less randomly associated, is passed over. The agglomerations of cultural items passed between social groups sometimes appear to be fortuitously associated in a similar way, like trousers with Western technology.

Mr. Maynard Smith's commentary, and the subsequent discussion, fastened on the empirical character of genetic transmission and mutation on one hand, and human history on the other, and not on the conceptual utility of Prof. Waddington's models. Prof. Wadding. ton's picture of an epigenetic landscape formed into watersheds, gullies and valleys by developmental controls is presumably a crude heuristic representation of a very complex process about which, even yet, little is known; it is a way not so much of explaining facts as of keeping what is to be explained in mind. Seen in this light, there is probably something to be gained by a method-starved science like sociology from such broad sketches, taken not as a means of suggesting testable hypotheses but as illustrations of the conceptual strategy employed in a related, and more sophisticated, discipline. Mr. Maynard Smith, however, chose to attack this-and by implication, any other-attempt to work from biological to historical explanation. The material differences he cited are not in dispute: the sub-human evolutionary system works with little or no transference of characteristics acquired metagenetically, whereas there is continuous alteration of social institutions and culture by the interaction of individuals with each other, with their social inheritance, and with their physical environment.

In fact many, if not most, of the sociological analogies quoted in Waddington's paper are very dubious parallels to the genetic and epigenetic models brought into play. The resilience and durability of Jewishness can scarcely be equated with lack of adaptability; this is a familiar sociological instance of cultural adaptation to manifest or latent subordination, along with the well-defined characteristic speech and manners of Negroes in the southern States of the United States: and the association of trousers with steam-engines and trading posts is only non-functional in a very restricted technological sense.

Maynard Smith took the view that the Marxist interpretation was the best attempt so far made at a usable theory of history, its weakness lying not in any fundamental error in Marx's own approach but rather in the failure of his followers to treat his ideas critically or to modify them in the light of advances in other fields. $\mathrm{He}$ did not think that one could usefully start from evolutionary theory and then attempt to find historical analogies for the various entities and items involved. Prof. Waddington, he said, had failed to point to any process in history comparable to natural selection, the most important single concept in the theory of evolution.

I have little doubt that a quick glance through the record of patented inventions, or the history of revolutionary epochs in England, France and Russia, even a reading of "Doctor Zhivago", would reveal plenty of instances of natural selection at work in the field of technological or political innovation. The crux of the difficulty lies, as Dr. J. Bronowski hinted at the end, in our present incapacity to isolate a single 'billiard-ball' entity from which to build explanations of variation in human society, as biologists have done with the gene- the unitary member of a pool of available characteristics constantly replenished by mutation and reduced by natural selection.

For Bronowski, this represented a failure by sociologists to respond to the challenge of Darwin's work. It was a double challenge, and a double failure. The first was the implicit question in his work of how variation occurred, a question which the later science of genetics was developed in order to answer. The second was the introduction of the notion of chance into rational explanation. This had, he claimed, proved a necessary foundation for the future not only of biology but also of physies.

In reality, chance has figured very largely in the historian's rendering of his subject. It accounts partly for the outlawing of pattern, interpretation, and theory by historians, and becomes explicit, though disguised, in the remark of H. A. L. Fisher's, quoted with such approval by K. R. Popper : "Men .. have discerned in history a plot, a rhythm, a predetermined pattern . . . I can see only one emerg. ency following upon another . . . only one great fact with respect to which, since it is unique, there can be no generalisations". But historians have used chance as a flag of surrender rather than as a weapon, and students of society have been content to name ten. dencies rather than establish laws. Prof. Morris Ginsberg's paper, "Social Evolution", was itself an 
admirable demonstration of the classic procedures of sociologists, and of the very different manner in which they have developed the concept of evolution and met the questions it poses. It discussed at some length attempts by nineteenth-century and later social scientists to develop evolutionary interpretations of the course of development of language and technology, and less successfully, of religion and law. He then presented his own view of social evolution as a process of development through higher levels of organized complexity of rational ideas, this process being effected by the human capacity for the intercommunication of ideas and skills.

Prof. Lancelot Hogben, by contrast, made his contribution on "Darwinism and Human Society in Retrospect" an exercise in the interpretative view of history he has made his own-which one would like to call philotechnic commensalism: the fortuitous concurrence and subsequent interaction of circumstances, generating complex causal processes which determine the direction and the variations in the rate of cultural development in different sections of the human species. The technological backwardness of the African is thus related to the susceptibility of horses to trypanosomiasis, which "has condemned Africans south of the tropic of Cancer to be their own beasts of burden in territories where malaria, yellow fever, hook-worm infection, schistosomiasis and many other diseases only lately recognized by medical science exact a heavy toll from the vitality of the people". Furthermore, "every change of the human environment through human interference signalizes a new accretion of transmissible experience and a now potential of further change. Because of this, human society is a unique ecological system". Thus, Darwin's work fits logically into its historical position when seen in the context of the stage reached by technological developments available in England by the midnineteenth century; the most significant circumstances being the greater facilities for sea travel offered by steam power, which "both greatly enlarged opportunities for a global survey of living beings and forced the problems of geographical distribution on the attention of naturalists", the accumulation of evidence for evolutionary succession provided by the work of survey and excavation undertaken during the railway-building period, and the major improvements in the microscope. The formulation and reception of Darwin's contribution to evolutionary theory similarly falls into place among the controversies over the criteria which should determine admission to the universities, the Civil Service, commissioned rank in the army and other controllerships, the debate over free competition as a principle of economic welfare and a social ethic, and the re-sharpening of the Abolitionist conflict in the years before the outbreak of the American Civil War.
In turn, the grand theological debates of the next forty years appear now to be locked firmly within their ideological setting; and the fruitless search for a complete genealogy of organic creation, Hogben also suggested, is visible now as the inescapable fate of a biology unprovided with the means of distinguishing adequately between hereditary transmission and genetic variation.

While Hogben's and Waddington's contributions inevitably dominated the conference, as latter-day reflexions by Darwin's scientific successors on the possibilities and limitations of a biological view of human society, other topics bulked larger than this short notice can easily show. Prof. Basil Willey's introductory account of the descent of Darwin's own theories from previous writings, although stretching back to Empedocles, was subject to a good deal of emendation in later discussions; his restriction of the effect of his work to the theological debate was deplored, and his view of Darwin's ultimate religious position as "helping to restore buoyancy to religion by forcing it to abandon some of its more untenable defences" was rejected by both rapporteurs. His paper also, however, bore on Darwin's introduction of the notion of chance into the rational interpretation of universal destiny, ideas far more disruptive than Newtonian mechanics, which had made the retention of the notion of design and of Designer plausible.

Mr. S. A. Barnett, in the last session, returned to the attack on Prof. Waddington's side with a range of suggestions from the study of the behaviour of bees, rats, birds and fish which might throw some light on behaviour in infancy, on motivation or emotion, and on the nature of language and human communication in general. Mr. Tom Burns, in the final paper, regarded these suggestions as limited to a very small field of human conduct, which characteristically selected courses of action from the wide range of possibilities available as normative guides to members of any society.

At the close of this conference, Dr. Bronowski remarked that no title could have lent itself better to so diverse an array of papers on such different subjects. Survivors of conferences on cybernetics may dispute this, but a conference which began with observations on the "history of man's endless probings into the mystery of existence; his thoughts about the nature of reality, about the administration of the universe ..." and ended with a muted discussion on chance as the mechanism of irreversibility, and thus as the instrument of the universal order apprehended by man, has some claim to catholicity. It was also, far more frequently than one expects any conference to be, absorbingly interesting and seminal.

The conference papers will be published in book form.

Tom Burns

\section{OBITUARIES}

\section{Dr. L. J. Spencer, C.B.E., F.R.S.}

Leonard James Spencer, who died on April 14 at the advanced age of eighty-eight, was fourth in a line of distinguished keepers of minerals in the British Museum. His predecessors were Story-Maskelyne, appointed the first keeper of the department a century ago, Sir Lazarus Fletcher and G. T. Prior. All three were Fellows of the Royal Society, to which Spencer also was elected in 1925. He was made C.B.E. in 1934, he was given the Murchison Medal of the Geological Society in 1937, and the Roebling Medal of the Mineralogical Society of America in 1941. $\mathrm{He}$ was an honorary member of the Mineralogical Societies of Germany and of America, a senior Fellow of the Geological Society of London, and was president of the Mineralogical Society during 1936-39, and its foreign secretary from 1949 until his death. 